\title{
A Model of Mobile Application for Automatic Fish Feeder Aquariums System
}

\author{
D. Prangchumpol
}

\begin{abstract}
Currently, ornamental fish in the office is popular among the fishers and fish farmers because this can create the good environment in an area. Thus, fishers have to pay attention in caring and control all kinds of factors such as feeding, air pumps, light, and $\mathrm{pH}$ value of water which may affect to the quality of water and fish maybe dead. With the advancement of IoT technology that is used to control wireless gadgets, this research developed an automatically fish feeding system that works through a mobile application. By writing device control commands onto the microcontroller device, users, through a mobile application, can control timing and amount of fish food according to the number of fish automatically, as well as warning when $\mathrm{pH}$ value of water is not proper. After testing from experts and users, the study found that an average value in the efficiency of this system was 4.16 which is considered that this application can control fish aquarium efficiently, and decreased spoiled water regarding to improper fish feeding.
\end{abstract}

Index Terms-Fish feeder, mobile application, aquariums system.

\section{INTRODUCTION}

Currently, fish aquariums in government offices, companies, tourist places, public parks, temples, schools, universities, and public areas is popular because this can improve the environment in the areas. Besides, fish aquarium can be used as a recreation place for students, teachers, and other people, and also support fis h farmers. However, over feeding can spoil water, which is needed to be solved, and fish famers needed to spend most of the time in caring lighting system and water changing, otherwise the water is spoiled and fish are dead. With the advancement of Inter of Things (IoT) Technology that can be controlled through a mobile phone, a researcher developed an automatically aquarium system that can be controlled through a mobile phone. This can help fishers in checking $\mathrm{pH}$ value of water in an aquarium, an amount of food, timing, lighting, as well as spoiled water according to over feeding. Moreover, this application can support the environmental conservation.

The paper is structured as follows. Section II mentions related work. Section III is methodology of this paper. Section IV is Result and Discussion. Finally, Section V contains the Conclusion and Future work.

Manuscript received April 30, 2018; revised Jun 19, 2018

D. Prangchumpol, Department of Information Technology, Faculty of Science and Technology, Suan Sunandha Rajabhat University, Bangkok, Thailand (e-mail: Dulyawit.pr@ssru.ac.th, dulyawit@gmail.com).

\section{RELATED WORK}

Efficient operation and management of power network require many tools. Distribution network is transforming traditional radiation into large-scale smart grid, which is characteristic of greater number of power, multi-contact, and more power flow [1].

Some researcher design and production of automatic Fish feeding which is installed in the fish pond in front of the Engineering Rajamangola University of Lanna technology, Northern Campus, Chiang Mai .We solve the problem about the lack person for management water of the fish pond. It doesn't has problemabout the water pollution in the pond [2]. Most of researcher try to monitoring and control the farm operation and environmental condition available. Sinduja presents a flexible answer in a trial of up the accuracy in observation the environmental conditions like temperature, water level, food feeding and reducing work force for industrial households poultry farm [3]-[9]. There is a lot of inventions had been made and been classified as "automatic fish feeder". From those previous designs, a few are chosen due to their criterions which are quite interesting and also useful. However, as stated by Mohapatra, Sarkar, Sharma and Majhi [10] and Noor, Hussian, Saaid, Ali and Zolkapli [11], for most automatic fish feeder, it is not easy to control the amount feed released. Too much will pollute the water in the pond or the tank. Furthermore, instead of feeder that are situated in pond, there are also automatic fish feeder feed feeder that are placed on the ocean by installing inside a buoy [12]. It is understandable that by placing the feeder inside a buoy on the ocean, by installing a camera, microphone or any other appropriate sensor, oceanic aquamarine life can be easily monitored. As long the ponds are large enough, such fish feeder can be used. P. Bartolome [13] in general fish farming the acidity and alkaline of the water should be maintained between 6 to 8 . Too acidic or alkaline will cause adverse effects, acid erosion of the gill tissue, tissue coagulation necrosis, increased mucus secretion, abdominal congestion and inflammation. If the $\mathrm{PH}$ value is less than 4.5, the fish will die. D.Yusuf Mulge [14] temperature sensor are used to deliver the temperature information on a fire extinguishers to website, email-id, and mobile phone number. In this manner, response to fire emergencies is made with in fraction of seconds. Wen-Tsai Sung [15] found that the amount of dissolved oxygen in water increases/decreases based on seasons. When the amount of dissolved oxygen in water is reduced below certain limit then fish growth will be hindered. When amount of dissolved oxygen becomes lower than the fish survival conditions the fish will die. Paraguas $M$ M [16] wireless networks have different security issues in the 
wireless communication. Wi-Fi Protected Access 2 (WPA2) uses Advanced Encryption Standard (AES) encryption an has more security compared to Wi-Fi Protected Access (WPA). Jayavardhana G [17] the buzzwords in Information Technology are Internet of Things (IoT). Internet of Things will transformreal world objects into intelligent virtual objects. Aim of IoT is to unify world under a common infrastructure, giving control of things around us. Gigli, $\mathrm{M}$ [18] the $\mathrm{pH}$ measurement is potentiometric that is, it explains the relationship between the electrode potential and the solution. The meter truthfully responds to the potential, it indirectly and mathematically converts the potential to the $\mathrm{pH}$ scale according to the questionable linear Nernst slope.

\section{MethodolOGY}

The development of an automatically aquarium through a mobile application is combined in 4 steps as follows:

\section{A. Study problems and possibility}

This process is reviewing through research papers and related studies in order to gather data and system development.

\section{B. Design and develop automatically fish aquarium}

This step divided into two parts. First is Design system and second is designing of a mobile application. A model of mobile application for automatic fish feeder aquariums system was show in Fig. 1.

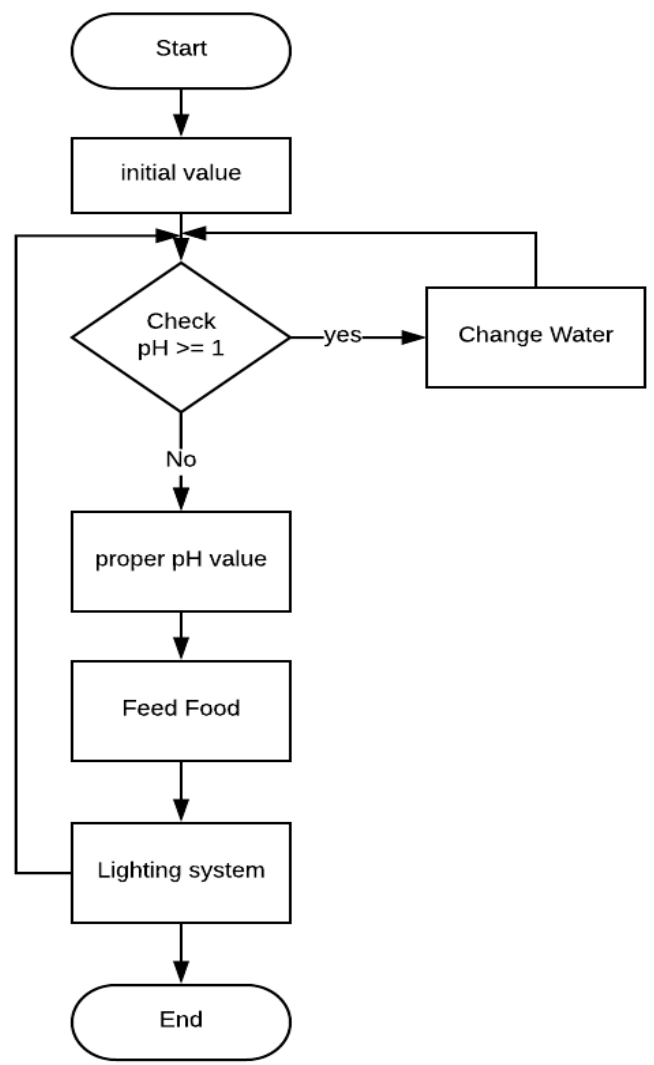

Fig. 1. A Model of mobile application for automatic fish feeder aquariums system.
1) Design system by writing down a procedure of $\mathrm{pH}$ value measurement, feeding system, and lighting. $\mathrm{pH}$ value of water can affect the quality of water in an aquarium. Fig. 2 show example of Raspberry pi broad and Fig. 3 show LCD circuit.

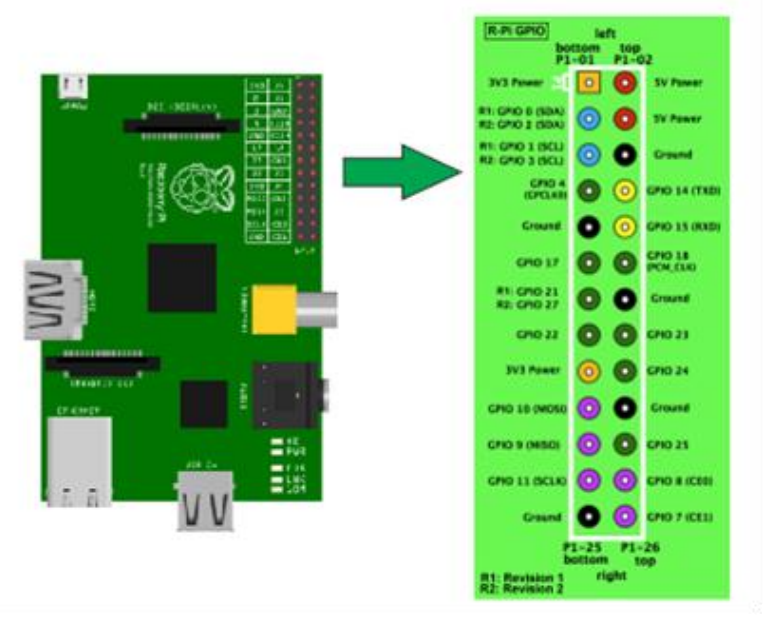

Fig. 2. Example of Raspberry pi broad.

2) $\mathrm{pH}$ value measurement can be used in water changing, and a researcher used $\mathrm{pH}$ value in changing water. The proper $\mathrm{pH}$ value is 6.5 to 9.0 .

3) Fish feeding was developed by using Raspberry pi to control automatically. Users can determine an amount of food and time.

4) Lighting systemwas developed by using Raspberry pi to control turn-on and turn-off the burbs in a fish aquarium based on the current time.

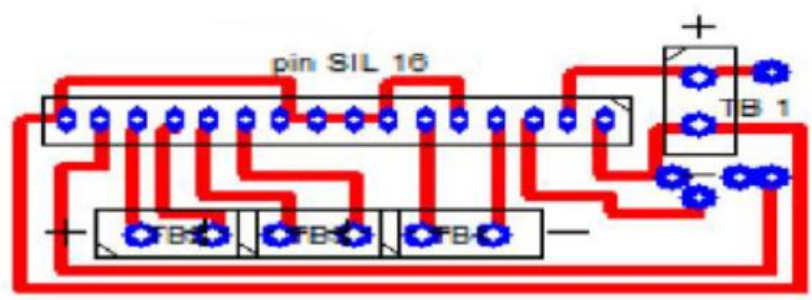

Fig. 3. Example of LCD circuit.

5) Designing of a mobile application This procedure was to design data base and visual image on a mobile phone monitor which is linked Raspberry pi with wireless gadgets.

\section{An Automatically Fish Feeding System}

Based on the design on a mobile application, a researcher writing an application by using $\mathrm{C \#}$ which a program control sensor in fish feeding, $\mathrm{pH}$ value measurement, and lighting. The data from the Raspberry Pi can be retrieved in real time, allowing users to check the current information. An example of Fish Feeder application was show in Fig. 4.

\section{An Automatically Fish Feeding System}

This research divided system testing into two parts: accuracy and satisfaction toward an automatically aquarium system. 


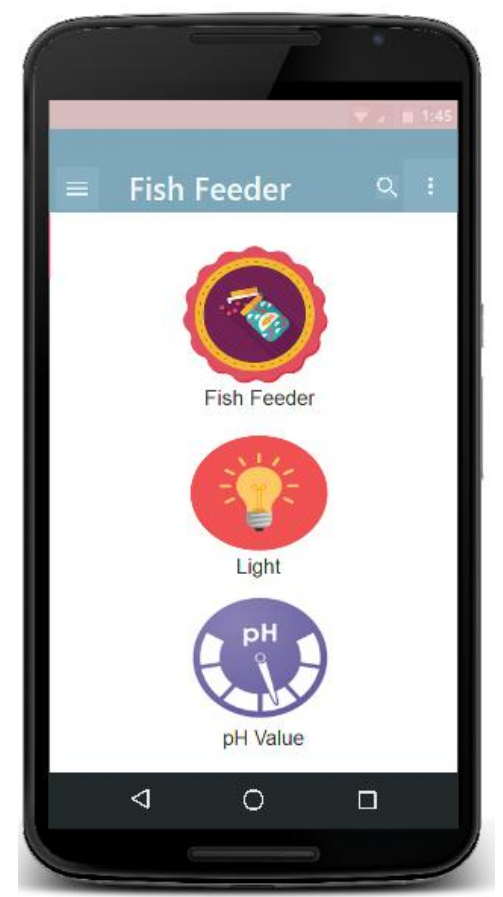

Fig. 4. Interface of Fish Feeder application.

\section{RESUlTS AND DISCUSSION}

The satisfaction was accessed by 35 experts through questionnaires and presented in a Table. 1. The subjects were asked to rate the relevancy of the search results on a five-point scale: Score 1 is the level of satisfaction improvement, Score 2 is minimum level of satisfaction, Score 3 is medium level of satisfaction, Score 4 is good and Score 5 is very good satisfaction. The result from the assessment in satisfaction of mobile application for automatic fish feeder aquariums system showed that system reliability and information was 4.16 and reliability was 057 . The result showed that the satisfaction toward a system was good.

However, the results score can be increase by develop and improve some additional features such as in the case of infectious diseases in the aquarium, serious consequences can be expected. This is an interesting research topic for future work.

T ABLE I: THE RESULT OF THE ASSESSMENT

\begin{tabular}{llll}
\hline \multicolumn{1}{c}{ Content } & Mean & S.D. & Result \\
\hline 1. sturdy & 3.82 & 0.63 & good \\
2. proper in use & 4.11 & 0.74 & good \\
3. modern & 3.90 & 0.88 & good \\
4. safety in using & 3.74 & 0.51 & good \\
5. save time & 4.32 & 0.73 & good \\
6. works for the purpose. & 4.28 & 0.21 & good \\
7. improve quality of life & 4.83 & 0.33 & Very good \\
8. accuracy in an application & 3.89 & 0.52 & good \\
9. convenience in using & 4.01 & 0.65 & good \\
10 Be able to use in the real time & 4.72 & 0.46 & Very good \\
\hline Average & 4.16 & 0.57 & good \\
\hline
\end{tabular}

\section{CONCLUSION}

This research is to develop a mobile application to control an automatically aquariumsystem. The result showed that this developed system could save labors of fishers. From the testing the system accuracy, it revealed that this application could work according to users' command, and could set time without turning off or unplugged the system. The system could feed fish on time, and also could control $\mathrm{pH}$ value of water properly. The systemcould alert users when $\mathrm{pH}$ value of water was lower than determined value, including turn on and off the light automatically. This study showed that an automatically aquarium can be used, and adjusted according to the size of an aquarium. The satisfaction of users was good. Further study should be done on an automatically water changing system.

\section{ACKNOWLEDGMENT}

The authors would like to thank Suan Sunandha Rajabhat University for scholarship support.

\section{REFERENCES}

[1] Y. M. Lu, D. Liu, and Y. H. Huang, "Feeder modeling and application based on CIM," in Proc. the CSEE, pp. 157-163, 2012.

[2] T. Pan-em, "Design and production of automatic fish feeding maching," 2014,

[3] K. Sinduja, S. S. Jenifer, M. S. Abishek, and B. Sivasankari, "Automated control system for poultry farm based on embedded system," in Proc. 2016. International Research Journal of Engineering and Technology.

[4] N. S. Amir, A. M. F. M. Abas, N. A. Azmi, Z. Z. Abidin, and A. A. Shafie, "Chicken farm monitoring system," in Proc. 2016 International Conference on Computer and Communication Engineering, Kuala Lumpur, 2016, pp. 132-137.

[5] S. Jindarat and P. Wuttidittachotti, "Smart farm monitoring using Raspberry $\mathrm{Pi}$ and Arduino," in Proc. 2015 International Conference on Computer, Communications, and Control Technology, Kuching, 2015, pp. 284-288

[6] T. Upachaban, A. Boonma, and T. Radpukdee, "Climate control system of a poultry house using sliding mode control," in Proc. 2016 International Symposium on Flexible Automation, Cleveland, OH, 2016, pp. 53-58.

[7] T. Fujii, H. Yokoi, T. Tada, K. Suzuki, and K. Tsukamoto, "Poultry tracking system with camera using particle filters," in Proc. 2008 IEEE International Conference on Robotics and Biomimetics, Bangkok, 2009, pp. 1888-1893.

[8] M. Ammad-uddin, M. Ayaz, E. H. Aggoune, and M. Sajjad, "Wireless sensor network: A complete solution for poultry farming," in Proc. 2014 IEEE 2nd International Symposium on Telecommunication Technologies, Langkawi, 2014, pp. 321-325

[9] Y. Wan, S. Yu, J. Huang, and J. Yang, "Automation integration for Taiwan country-chicken farm management using field server," Presented to Iaald Afita WCCA 2008 World Conference on Agricultural Information and IT.

[10] B. C. Mohapatra, S. Bikash, K. K. Sharma, and D. Majhi, "Development and testing of demand feeder for carp feeding in outdoor culture system," Agricultural Engineering International: the CIGR Ejournal. Manuscript, no. 1352, 2009.

[11] M. Z. H. Noor, A. K. Hussian, M. F. Saaid, M. S. A. Ali, and M. Zolkapli, "The design and development of automatic fish feeder system using PIC microcontroller control and system," Graduate Research Colloquium, 2012.

[12] J. B. Stanley and D. I. James, Aquaculture Feed Buoy Control-Part 1: System, 2006.

[13] P. Bartolome, Fallout of PH Value in Fish Farming, 2014.

[14] Y. M. Poonam and Y. Mulge, "Remote temperature monitoring using LM35 sensor and intimate android user via C2DM service," International Journal of Computer Science and Mobile Computing, vol. 2, no. 6, 2013, pp. 32- 36.

[15] W. T. Sung, Effects of Dissolved Oxygen on Aquaculture, 2012. 
[16] M. M. Dey, F. J. Paraguas, P. Kambewa, and D. E. Pemsl, "The impact of integrated aquaculture - Agriculture on small - scale farms in Southern Malawi," Agricultural Economics, vol. 41, no. 1, 2010, pp. 67-79

[17] J. Gubbi, R. Buyya, S. Marusic, and M. Palaniswami, "Internet of things (IoT): A vision, architectural elements, and future directions," Future Generation Computer Systems, vol. 29, no. 7, 2013, pp. 1645-1660.

[18] M. Gigli and S. Koo, "Internet of things, services and applications categorization," Advances in Internet of Things, 2011.

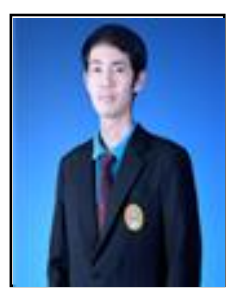

D. Prangchumpol was born in Thailand in 1980 . He received his B.Sc. in statistic from Thamasat University, and M.S. in computer science from SlipakornUniversity. He received his doctorate degree from Chulalongkorn University in 2016 in the field of computer science and information technology. He works as a lecturer in major information technology in Faculty of Science and Technology, Suan Sunandha Rajabhat University. His researches are in the areas of virtualization system, network system, data analysis, and data mining. 